\title{
Do Asylum-seekers Respond to Policy Changes? Evidence from the Swedish-Syrian Case*
}

\author{
Henrik Andersson ${ }^{\dagger} \quad$ Kristoffer Jutvik ${ }^{\ddagger}$
}

December 12, 2019

\begin{abstract}
This paper uses quasi-experimental evidence to understand how changes in asylum policy affect the number of asylum-seekers. We look specifically at a sudden, regulatory change in the Swedish reception of Syrian asylum-seekers. The change took place in September 2013 and implied that all Syrian asylum-seekers would be granted permanent instead of temporary residence permits. Using high-frequency data and an interrupted time-series set-up, we study the extent to which this change caused more Syrian citizens to apply for asylum in Sweden. The paper provides several new insights: Our estimates show a clear and fast increase in the number of lodged asylum applications in Sweden after the policy change. The increase had implications for the distribution of Syrian asylum-seekers in Europe, but only in the short term. We argue that the lack of a clear long term effect on the European distribution is mainly due to culminating constraints on the Swedish bureaucracy from increasing processing times for Syrian asylum-seekers. Also, the change caused a shift in the share of adult men arriving without a household member, and consequently in the share of refugees applying for family reunification. The effect on family reunification was not limited to the short run but remained stable over the following years.
\end{abstract}

Keywords: Refugees, Asylum Policy, Sweden, Residence Permits

JEL classification: F22, J15, R23, R31

${ }^{*}$ We are grateful to Matz Dahlberg, Gunnar Myrberg, Cristina Bratu, Per Engström, Torsten Santavirta, Karin Edmark, Per-Anders Edin, Albert Saiz, Linuz Aggeborn, Mattias Öhman, Per Adman, seminar participants at the 2018 APSA meeting in Boston, the ENHR meeting of 2018, the Institute for Housing and Urban Research and the Department of Economics at Uppsala University for helpful suggestions and comments. We are also very thankful for all the help provided by staff at the Swedish Migration Agency. Henrik Andersson is also grateful to funding from the European Research Council, grant number 683214 CONPOL. Declarations of interest: none

${ }^{\dagger}$ Uppsala University (Department of Government). mail: henrik.andersson@statsvet.uu.se

${ }^{\ddagger}$ Uppsala University (Institute for Housing and Urban Research and Department of Government) mail: kristoffer.jutvik@ibf.uu.se 


\section{Introduction}

The relevance of "responsibility-sharing" in the field of refugee reception policy has become increasingly central from a European perspective. On the one hand, in a system where asylum-seekers, to some extent, select hostdestinations after entering the EU, it has been suggested that the national state has no or less control of its own borders (Soysal, 1994; Sassen, 1996, 1998). On the other hand, it is apparent how a number of countries develop comparatively restrictive policy structures and attitudes towards migrants and asylum-seekers, for example, using visa requirements and border checks, which may, in turn, affect migration flows to specific destinations (Böcker and Havinga, 1998; Freeman, 2004; Castles et al., 2014). The effectiveness of such policies is further heavily dependent on what migrants know about countries they go to, and how much such knowledge enters their decisionmaking process.

A large body of literature with contributions from political science, economics, and sociology, has sought to understand if refugees respond to host country policies, and to what extent. Until this point, a large proportion of previous studies can be divided into two broad approaches: One quantitative branch, which first and foremost has relied on estimations of cross-country differences in the number of asylum-seekers as a function of both source and destination country institutions and policies. ${ }^{1}$ The other, qualitative approach, has mainly drawn inference from interviews with migrants to better understand in what way and to what extent host country policies matter for the decision on where to go. ${ }^{2}$ Although both of these approaches provide plenty of valuable insights, it is essential to understand further how destination country policies cause changes in asylum flows, the time frame of such responses, and if effects are different across individuals with varying characteristics.

In this paper we therefore take a different approach. Using a sudden change in Swedish residence permit policy with regards to Syrian citizens, we estimate the effect of the change in policy on the number of Syrian asylum-seekers going to Sweden. Briefly, the policy change, which was implemented in September 2013 (RCI 14/2013, 2013), meant that all asylum-

\footnotetext{
${ }^{1}$ See Neumayer (2004); Thielemann (2006); Moore and Shellman (2007); Hatton (2009, 2016); Keogh (2013); Brekke et al. (2017).

${ }^{2}$ See Collyer (2005); Gilbert and Koser (2006); Crawley (2010).
} 
seekers from Syria were granted permanent instead of temporary residence permits. Besides providing permanent shelter, the policy change implied that asylum-seekers could seek family reunification after a residence permit was granted. Compared to other European states, the change made Swedish assessments of Syrian asylum applications unique and liberal and the new directives were reported in international media instantly after implementation. In order to evaluate the effect of the new policy, we use an interrupted time-series approach to estimate the change in number of asylum applications in Sweden as well as the distribution of asylum-seekers among the two major European recipients: Germany and Sweden. The sudden change of policy combined with high-frequency data allows us to evaluate the effect causally already within weeks of the policy change.

The possibility of estimating the immediate causal impacts of migration policy is a distinct new feature we believe this paper brings to the literature: Current quantitative papers struggle with providing causal effects since all cross-country comparisons suffer more or less from endogeneity issues. ${ }^{3}$ Our set-up should also be instructive on how fast information on asylum policy changes travels as well as enters the decision margin of those affected. Furthermore, the current literature most often uses yearly data, which can be problematic given the seasonal patterns of migration. ${ }^{4}$

Besides our focus on the number of asylum-seekers, we consider the traits of the asylum-seekers. In other words, we study if increasingly beneficial migration policies attract specific categories of migrants after implementation. The study of migrant characteristics before and after a policy change, utilizing detailed individual registry data, is a second novel feature of the paper. Also, we show first suggestive evidence on the effect of processing times on the share of asylum-seekers.

In a broader sense, this study adds not only to the academic debate on determinants of migration flows, but it is also relevant from a policy perspective, suggesting how even medium alterations of national policy can

\footnotetext{
${ }^{3}$ See Brekke et al. (2017) and Görlach and Motz (2017) for a discussion on identification.

${ }^{4}$ That said, our presumed improvement in identification implies a trade-off: The identification relies on the possibility to observe outcomes just before, and just after the policy change. The before and after strategy becomes less valid as time passes, and we move further from the point in time of the policy change. In terms of a long term effect, endogeneity concerns remain an issue. Nevertheless, we do provide both estimations and figures which show the post-reform development until the summer of 2015.
} 
have major effects on migrant inflows. Such knowledge may be of utmost importance in the process of planning and implementing reception policies on both the national and supranational levels of government.

The paper provides three main empirical results.

First, the results clearly indicate that Syrians reacted to the policy change; the weekly number of asylum-seekers to Sweden almost doubled within 2013. This change also affected the distribution of Syrian asylumseekers within Europe; the share applying in Germany dropped as the numbers in Sweden increased. Importantly, the policy also had a substantial effect rather fast. Already within a couple of weeks, the number of asylumseekers had significantly increased. The fact that effects are seen already within weeks might have implications for the interpretation of studies using year-to-year variation in policies.

Second, the policy changed the traits of those arriving. We first show that the share of highly educated asylum-seekers increased after the policy. We explain this with the stronger economic resources, as well as the on average better access to information held by the more educated. Most importantly, however, we show that the share of households arriving together dropped. We argue that this was due to the new possibility of family reunification, which was not an option available for all prior to the policy change. We support this story further by showing a long term upward shift in the share of eligible Syrians who applied for family reunification after the policy. The latter increase has two major implications: It gives support to theories treating the migration decision as a household decision (see Massey et al. (1993)); and estimations of the effect of changes in asylum policy should always take into consideration a potential family spillover effect.

Third and last, the share of Syrians applying for asylum in Sweden dropped over the second half of 2014. We explain this with the drastic increase in processing times of a Syrian application in Sweden over the relevant period. We further provide a reduced form elasticity between processing times and share of asylum-seekers, which turns out to be strongly negative. While not providing causal evidence, the result suggests an interesting relationship between bureaucracy constraints and the number of asylum-seekers.

The study has the following structure: The next section gives an overview of previous research, after which we discuss the policy change as well as 
other institutional details in the Swedish-Syrian case. Section 4 describes the empirical approach, section 5 gives the results and section 6 concludes.

\section{Does migration policy affect the migration de- cision?}

There is a long line of research with the specific aim of understanding the international flows of asylum-seekers. Within this line of research, negative aspects in countries of origin or positive aspects of host-destinations, so-called push and pull factors, have largely been used as prevalent explanations to observed migration patterns. Simply put, push factors are generally defined as any structural reasons causing individuals to move out of a place, while pull factors represent any factors attracting individuals to a destination (Zimmermann, 1996).

The framing of migration as an individual decision based on push and pull factors have faced critique, with researchers instead promoting the idea of migration as a household decision, of the importance of path-dependent networks (Massey and Garcia, 1987), and of institutional features, where the individual decision-margin is downplayed all together (Piore, 1979). As noted by Massey et al. (1993) there is, however, no reason to expect that these theoretical predictions are mutually exclusive. The relationship between migration trends and different structural factors should instead be decided trough empirical investigations. ${ }^{5}$

A common research design in economics have been to use panels of host and source countries and regress the in-between country flow of asylumseekers or refugees on the economic, social, and political values both in the source and host country. Generally, the results from these studies tend to support the idea that push factors outweigh pull factors as an explanation for the great flows of asylum (Hatton, 2009, 2016). As far as pull factors go, some are fixed or historically dependent and clearly outside the scope of any policy-maker, such as geographical distance, a common language, whether

\footnotetext{
${ }^{5}$ Here, it should be noted that an underlying assumption in many push and pull models, is that the asylum-seekers have fairly extensive knowledge about the potential destination countries. This assumption has, however, been critiqued and questioned by a number of studies (Gilbert and Koser, 2006; Crawley, 2010; Mayblin, 2016; Böcker and Havinga, 1998). We will return to this point in the next section, where we demonstrate that information about the policy clearly spread.
} 
the source country is a former colony or not, or the size of the ethnic enclave at the destination (Neumayer, 2004; Thielemann, 2006). There is also some evidence that economic factors, such as unemployment (Thielemann, 2006), or income level (Moore and Shellman, 2007; Keogh, 2013) at the destination matters.

The above and other studies have also addressed the effectiveness of migration policy as a pull or deterrence measure. A common design has been to use yearly data and study the effect of recognition rates on asylum flows. ${ }^{6}$ Papers using this method have tended to find small but significant effects, suggesting that lower recognition rates are correlated with smaller asylum flows in the same or later years (Neumayer, 2004; Keogh, 2013). A more detailed focus on different types of policies is found in Thielemann (2006), and later Hatton (2009), who provides a taxonomy of three different kinds of migration policy: policies related to physical entrance into the country, the application process and welfare policies. ${ }^{7}$ While Hatton $(2009,2016)$ find deterrent effects from stricter border control and asylum processes, but not from welfare changes, Brekke et al. (2017) and Thielemann (2006) find that access policies only have a minor effect, while stricter welfare policies can have a clear deterrence effect.

A recognized issue with cross-country studies is endogeneity. As is noted by Brekke et al. (2017), this may be the result of spillovers over time within a destination country: Consider, for example, an increase in asylum flows from country $i$ to country $j$ in period $t$. Due to the increased pressure, country $j$ changes policies, perhaps by lowering recognition rates, or adopting stricter access policy measures. Two opposing effects will now occur: First, a policy effect, which potentially decreases the number of applicants. Second, a network effect, which implies that the higher number of applicants from country $i$ in period $t$ makes it easier for other applicants from country $i$ to come in period $t+1$. A model regressing the number of asylum-seekers on, for example, recognition rates might therefore underestimate the effect of the policy.

A second source of endogenity may come from spillovers across coun-

\footnotetext{
${ }^{6}$ The recognition rate is generally defined as the share of all applicants who are granted a residence permit.

${ }^{7}$ Policies on the process of application refer to rules regarding the status of a refugee, most often empirically captured by the already mentioned recognition rate. Welfare policies include the generosity of the welfare system, conditional on having a residence permit.
} 
tries. Consider a change in policy from destination country $j$, making asylum policy more strict. This may lead to an increased flow to substitute country $j-1$, causing country $j-1$ to increase asylum policy strictness. As is discussed by Bratu et al. (2018) and Görlach and Motz (2017), this strategic interaction between substitute countries violates the assumption of independence between observations, and may lead to biased estimates.

Our approach solves the identification problem by combining a sudden change in policy within one destination country with the use of highfrequency data. ${ }^{8}$ As is the case for any solution, it has some drawbacks. ${ }^{9}$ However, given the current lack of quasi-experimental evidence, we believe our approach to be a relevant addition and a good complement to the crosscountry studies. Also, there is little or no knowledge on how fast refugees may react to policy changes. Such knowledge is of course only possible to obtain through high-frequency data. ${ }^{10}$

\section{The policy and the Syrian case}

Before going into the methodological setup, this section describes the institutional background, including the development of the Syrian conflict and the directives provided by the Swedish Migration Agency (SMA).

\subsection{Developments and directives of the conflict in Syria}

Starting in late 2011, as the Syrian conflict rose in intensity and scope, the SMA crafted a number of internal documents containing guidelines and de-

\footnotetext{
${ }^{8}$ We are only aware of one quantitative study focusing on changes within one country. Holzer et al. (2000) investigate the relationship between increasingly restrictive migration policies on the inflow of asylum-seekers into Switzerland in the first part of the 1990s. The authors find that restrictive policies is associated with a lower inflow of migrants.

${ }^{9}$ For example, the method relies heavily on the use of high-frequency data. Also, as already mentioned, the possibility to identify the effect of the policy as opposed to other, confounding factors, becomes less reliable over the long term.

${ }^{10} \mathrm{An}$ alternative way forward is to use a structural approach. Görlach and Motz (2017) formulate a dynamic life cycle model, and estimate the effect of recognition rate changes in a set of destination countries, on refugee inflow from Syria. In line with Hatton (2009), the results point to a deterrent effect of lower recognition rates on asylum flows. While such approaches are another promising way forward, structural estimation techniques usually have to make several assumptions on behavioral patterns, including the time lag between policy changes and migratory responses. At the very least, quasi-experimental reduced form evidence complement these approaches by providing a better and more valid basis for the assumptions.
} 
scriptions of recent developments in the conflict referred to as RCI (Instructions from the General Counsel). ${ }^{11}$ These documents serve as guidelines in decision-making and rely on information from internal as well as international sources such as the United Nations High Commissioner for Refugees (UNHCR). In December 2011, the General Counsel of the SMA stipulated that the conflict in Syria was not considered to be an armed but a severe conflict (RCI 32/2011, 2011). This meant that the SMA did not consider the Syrian conflict in itself to be of such magnitude that asylum applications generally should be granted. A few months later, in January 2012, the General Counsel decided to hold all expulsions of Syrian citizens (RCI $1 / 2012,2012)$ as the conflict had become more intense. These directives were followed by similar recommendations by UNHCR in March 2012.

Later, in June 2012, given reports of an escalation in the conflict, another document (RCI 14/2012, 2012) stipulated that there was a situation of general violence in the country. The SMA stated that even if reports from independent sources obstructed a uniform and detailed overview of the situation, the conflict was to be considered as extremely severe. In other words, the judgment by the SMA at this time was that any person, merely by being situated on Syrian territory, risked such treatment as stipulated in the Swedish Aliens Act. This is a central statement as it meant that all Syrian applicants should be granted asylum and therefore a residence permit. Of these, approximately 7 out of 10 applicants were granted subsidiary protection status and temporary residence permits, allowing three years of residence. The remaining, approximately 3 out of 10 applicants, were granted refugee status and permanent residence permits. ${ }^{12}$ These directives were in many regards in harmony with immigration policies in the rest of Europe, even though the length of the Swedish permit was longer.

\footnotetext{
${ }^{11}$ In Swedish: "Rättschefens instruktioner".

${ }^{12}$ There are two categories of protection in the Swedish Aliens Act (that are relevant for this study), refugees and persons in need of subsidiary protection. In accordance with the Geneva Convention, a person is a refugee if he or she has a well-founded fear of persecution due to race, nationality, religious or political beliefs, gender, sexual orientation or affiliation to a particular social group. Subsidiary protection status, refers to persons being at risk of death penalty, being subjected to corporal punishment, torture or other inhumane or degrading treatment or, as civilians, risk injury or death due to an armed conflict. Persons that fulfill the prerequisite in any of the above categories have the right to obtain temporary or permanent residence permits. Normally, persons in need of protection obtain permanent residence permits. However, if the permit is granted due to an armed conflict, temporary permits may be granted given the scale, intensity and durability of the conflict (RCI 14/2012, 2012; RCI 14/2013, 2013).
} 


\subsection{The policy change}

About a year later, in September 2013, the SMA made a new evaluation of the conflict in Syria (RCI 14/2013, 2013). The General Counsel stated that the conflict was still imprinted by a situation of general violence as described in the former RCI from 2012. However, at this time, the SMA had reliable information about the severity of the conflict, confirming the atrocities. It was further stated that the conflict was in a deadlock position, in which both sides believed near victory was possible and that the number of actors participating in the conflict had increased. Given the situation of general violence and increased complexity of the conflict, the General Counsel made the judgment that the unrest in Syria would go on for an extensive period of time and stated that all Syrian asylum-seekers should be granted permanent residence permits. For the individual applicant, the change meant, besides gaining a secure residence status, the possibility to apply for family reunification. Holders of a temporary residence permit did not have this option.

A few important details and implications should be noted regarding the policy change. First, the decision was made by the SMA, and was hence not a party-political decision. This is important since the decision was not the result of a long parliamentary debate, or political discussion, making it practically impossible to react to the change in directives before the actual implementation. Second, the change was de facto implemented. Before September 2013, approximately 3/10 Syrian residence permits were permanent, which changed to $10 / 10$ after the reform. A detailed view of this development is seen in Figure 1. Third, from a European perspective, the changed directives stood out as unique and liberal. To the best of our knowledge, there was no parallel change in migration policy from other countries in Europe. Fourth, the policy change was immediately reported in media both nationally (Swedish Radio, Dagens Nyheter, and Expressen) and in international media such as BBC and Al-Jazeera. ${ }^{13}$ Essentially then, information about the reform was readily available for anyone seeking it, already the next morning. The impact of the policy change is suggested in Figure 2 , which visualizes the relative search interest for the Arabic translation of "Sweden" and "Germany" on Google, in Syria over 2013. The frequency

\footnotetext{
${ }^{13}$ Swedish Radio is the public service radio broadcasting company in Sweden. Dagens Nyheter and Expressen are two of the largest daily newspapers in the country.
} 
Figure 1: The share of permanent residence permits among all granted residence permits (among Syrian applications)

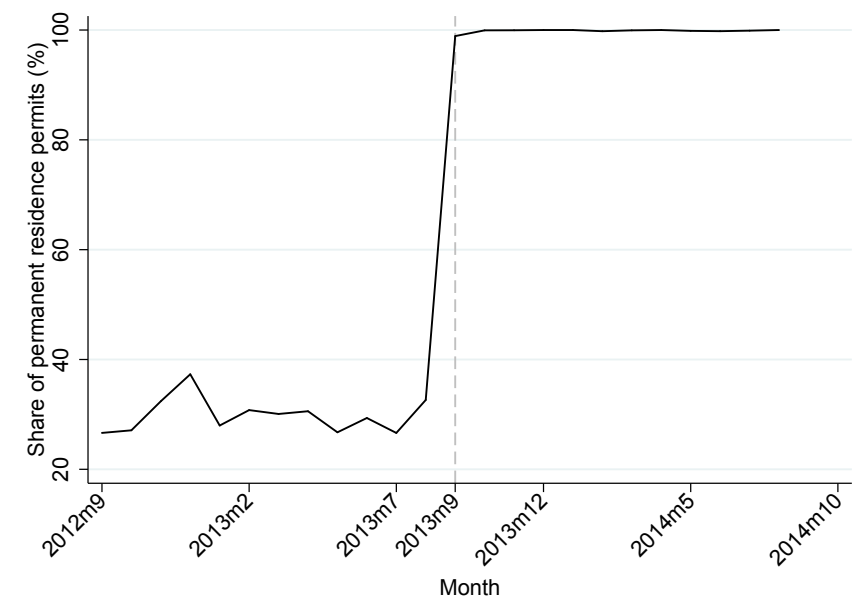

Note: Share of permanent residence permits among all granted residence permits. Data concerns distribution among Syrian applications only. Note that the recognition rate was $100 \%$ before and after the policy change.

Source: Swedish Migration Agency.

of searches for "Sweden" increased with $83 \%$-units over the two weeks following the policy change while the relative search interest for "Germany" stayed at low levels. The search interest for "Sweden" remained high before it returned to its pre-change level at the end of the year. We also see an increase in searches made in Lebanon and Turkey, harboring large populations of Syrian refugees, in the week of implementation. ${ }^{14}$ Another indication that the information reached the general public in Sweden and elsewhere is the number of visits to the homepage of the SMA, which peaked in September 2013 with 200,000 more visits compared to the second-highest point (monthly), and almost 500,000 more visits than the average month over the year. ${ }^{15}$

\footnotetext{
${ }^{14}$ We have also investigated the search interest for a number of terms, such as "residence permit", "asylum Sweden", "migration policy", "Swedish Migration Board", but due to insufficient data coverage we have not been able to see any changes in search interest over the time period.

${ }^{15}$ Information provided by the SMA.
} 
Figure 2: Relative search interest for Arabic translation of "Sweden" and "Germany" on Google search in Syria

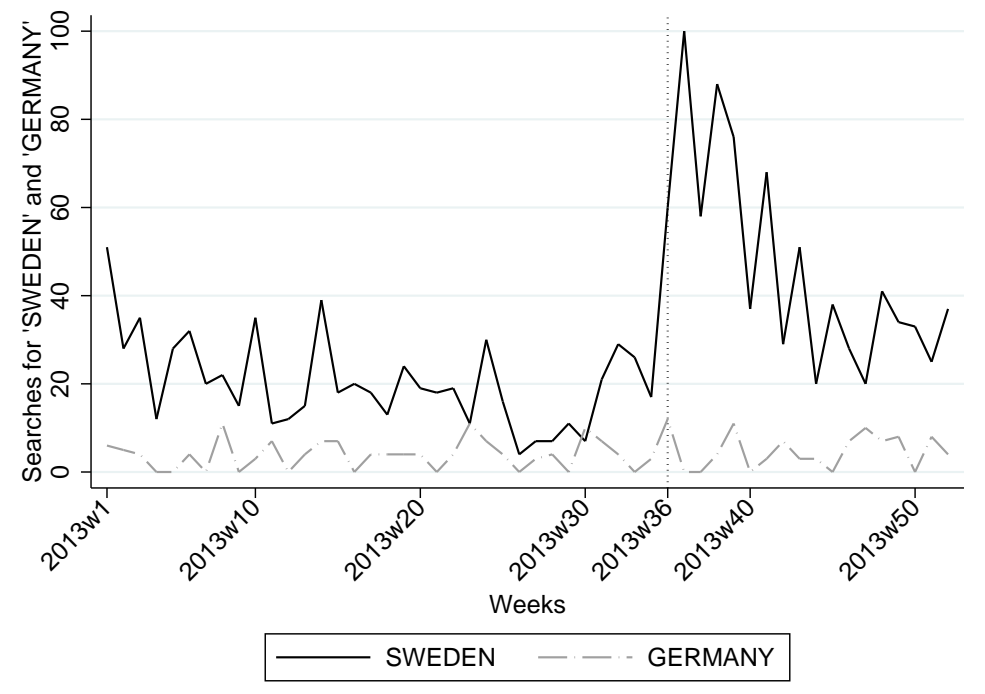

Note: The figure displays the relative search frequency in relation to the highest point in the graph. The value of 100 marks the highest interest.

Source: Google Trends.

\subsection{The route: Journey from Syria to Europe}

At the end of 2014, Syria had become the world's major origin country of refugees with 8 million Syrian citizens internally displaced and more than 4 million refugees outside the country. Although most Syrians fled (and still flee) to the neighboring countries of Turkey, Lebanon, Jordan, and Iraq (UNHCR, 2016), many attempted to travel further into the European Union with the aim to apply for asylum. The accumulating concentration of migrants at the border of the EU put significant pressure on the main entry points of Italy, Greece, and Hungary. In total, there were 770,000 irregular border crossings into the EU reported between 2010 and 2015. Recent reports indicate that most asylum-seekers only transited through the above countries on their journey towards the northern part of the EU, of which Germany (largest absolute migration from Syria) and Sweden (largest per capita migration from Syria) have been the most popular destinations for Syrians (ESPON, 2015).

In order to enter the EU, asylum-seekers from Syria have relied on irregular border-crossings using mainly two routes; the Central Mediterranean 
route and the Eastern Mediterranean route. First, the Central Mediterranean route goes from Libya to Malta and Italy. Between the years of 2010 - 2015, there were over 50,000 irregular border-crossings by Syrian citizens reported on this route. Syrian migrants arriving in Italy were normally asked for fingerprints by the authorities. However, as stated by respondents in interviews, many left before a claim for asylum was initiated to travel further and hand in their application in other countries (Jörum, 2015). ${ }^{16}$ The journey from Italy to Sweden has been described as being rather uncomplicated and made with the help of public transportation (Jörum, 2015).

The second route, the Eastern Mediterranean route, goes through Turkey - harboring almost 2 million Syrian refugees - to Greece. This route had over 60,000 reported irregular border-crossings by Syrian citizens between the years of 2010 and 2015 (ESPON, 2015). Syrian refugees in Greece have stated that they left fingerprints knowing that it would not change their possibilities to apply for asylum in other European countries (Greece is since 2011 exempted from the Dublin regulation). The route from Greece to Sweden is described as more complex compared to the route from Italy, going through Macedonia and Serbia, before entering EU via Hungary with the help of human smugglers (Jörum, 2015). We visualize the two main routes to Europe from Syria in the Appendix, in section A, Figure A.1.

Ideally, we would like to estimate the average time it would take for a Syrian asylum-seeker to go to Sweden. However, how fast an individual can react to the policy will depend on which route that is chosen, and where the individual is located when the policy is instigated. Particularly, we expect individuals already in Italy or close to Italy on the central Mediterranean route, to be able to react quickly, perhaps even within a week. For those still in Syria, it is reasonable to expect much longer time lags.

\section{Empirical method and data}

We now turn to the empirical set-up of our study. To estimate the causal effect of the policy change on the number of Syrian asylum-seekers to Swe-

\footnotetext{
${ }^{16}$ Italy is a part of the Dublin Regulation, which states that the country in which asylum is first applied for, is also the country that is responsible for rejecting or accepting the application. An individual who has turned in an application in country A can hence not restart a new application process in country B.
} 
den, we make use of an interrupted time-series design. ${ }^{17}$ The design uses two key features:

First, we must have a clearly defined point in time of intervention. For our baseline estimate, which uses weekly data, this point in time will be the 36 th week of 2013 . We also do monthly estimates and use the month of September as the intervention point. Both points in time are reasonable, given that the change took place early in the 36 th week, which was also the first week of September.

Second, we need data on the outcome (in our case number of asylumseekers from Syria) before and after the intervention. For this, we have collected data from the SMA on the weekly number of Syrian asylum applications over the period 2010-2016. For validity checks, we have also collected applications from the ten largest source countries for asylum besides Syria. ${ }^{18}$ The data will be used to create an underlying time trend of the number of asylum-seekers. Let $T$ be the number of weeks passed since the start of the

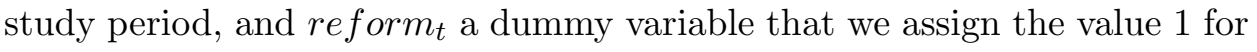
all observations after the intervention. Our outcome is \#asylumseekers $s_{t}$, which measures the weekly number of asylum-seekers from Syria to Sweden. In detail, we fit the following equation:

$$
{\text { \# } \text { asylumseekers }_{t}=\beta_{0}+\beta_{1} T+\beta_{2} \text { reform }_{t}+\beta_{3} \text { reform }}_{t} * T+\epsilon_{t}
$$

In Equation 1, $\beta_{1}$ represents the effect of the underlying time trend, while $\beta_{2}$ gives the level effect of the reform. $\beta_{3}$ is an interaction term capturing any change in the trend after the reform. The effect is hence measured comparing the situation before and after the reform, given the underlying linear trend, as well as the change in the trend after the reform, in the number of asylum-seekers. We will primarily consider effects using 2013 as our time-frame, but also provide graphs and results on the development up until the summer of 2015. All regressions use Newey-West standard errors.

Note also that the simple version of the model shown in Equation 1, conditions on a linear trend. It is fully possible to expect the trends to be non-linear. We will, therefore, also perform regressions with higher-order polynomials.

\footnotetext{
${ }^{17}$ For a good introduction to the method, see Bernal et al. (2017).

${ }^{18}$ For information on other data-sources used, we refer to the Appendix, and section E.
} 


\subsection{Empirical considerations}

Given the sudden change in policy and the high-frequency of the data, the interrupted time-series design is a convincing way to capture the causal effect of the policy change on the number of asylum-seekers from Syria. While it is possible that other time-confounders could affect the estimation results, we argue that these are unlikely to be an issue in our setting.

First, the increase of Syrians into Sweden should be specific to Syrians, and not a general increase of asylum applications from all source countries to Sweden. As a robustness check, we, therefore, add a control group, looking at the change in Syrian applications compared to the general increase of applications from other large sending countries. Specifically, we consider the top four asylum countries besides Syria, which during this time were Afghanistan, Eritrea, Iraq, and Somalia. The average number of applications from these countries then form a control group, which is seen in the multiple group model in Equation 2.19

$$
\begin{aligned}
& \text { \#asylumseekers } s_{t}=\beta_{0}^{M}+\beta_{1}^{M} T+\beta_{2}^{M} \text { reform }_{t}+\beta_{3}^{M} \text { reform }_{t} * T+ \\
& \beta_{4} Z+\beta_{5} Z * T+\beta_{6} Z * \text { reform } \text { fof }_{t}+\beta_{7} Z * \text { reform } \\
& t
\end{aligned}
$$

To the already described terms, we add $Z$; a dummy taking the value 1 for the treatment group, Syria, and the value 0, for the control group (Afghanistan, Eritrea, Iraq, and Somalia). $\beta_{4}$ gives the difference in the intercept of Syrian asylum-seekers and the control countries, prior to the intervention. The difference in the trend, or the slope, is given by $\beta_{5}$, and $\beta_{6}$ shows the difference in the effect of the reform between Syria and the control countries. Last, $\beta_{7}$ shows the difference between the slope after the reform. In this case, $\beta_{6}$ is the main coefficient of interest, providing a difference-in-differences style estimator. As will be clear from the graphical illustration of this model in Figure 3, the number of asylum-seekers from the control group countries neither increased nor decreased over the intervention line. ${ }^{20}$

\footnotetext{
${ }^{19}$ See Linden (2015) for a full description on the multiple group interrupted time-series model.

${ }^{20}$ It should be noted that a requirement for identification in a difference in differences set-up, is that there are no spillovers between the treatment and control group (SUTVA). This assumption could be threatened if the number of asylum-seekers from countries in
} 
Second, we want to make sure that an increase in the number of Syrian asylum-seekers does not reflect a general trend in Europe. If substitute countries to Sweden (mainly Germany) changed legislation or altered the general strictness of their migration policy, it can have spillover effects on Sweden. The control group approach in Equation 2 provides a good test for this as well, since if large general asylum policy changes occurred in substitute countries, we would expect the number of control group country asylum-seekers to Sweden to increase or decrease as a response. To further account for this, we make use of the DEMIG POLICY database, an extensive policy database covering migration-related regulatory changes in 45 , mostly high-income countries between 1945 and 2014. The database covers 6,000 changes, including the one studied in this paper. ${ }^{21}$ Looking at all changes made during 2013, there were no other large scale changes such as the Swedish one, which targeted asylum-seekers. ${ }^{22}$

Third, we need the severity of the conflict in Syria to remain at a similar level. Should the conflict become more severe over time, any increase in asylum applications could reflect the increased intensity of the conflict rather than the liberalization of Swedish policies. It is hard to find weekly or even monthly estimates of the severity of the Syrian conflict. However, using data from humanitarian tracker, we run a robustness test in which we add a control, which measures verified causalities in Syria per month. These estimates are found in the Appendix, in section C, Table C.2, and do not affect the results. Also, we will further look at the distributional change in Europe, studying the change in the share of asylum-seekers who opts for Sweden, rather than the main alternative country: Germany. For these estimates, the intensity of the conflict is arguably a less important covariate than when studying the absolute number of Syrian asylum-seekers. We also note that the change in policy occurred primarily as a response to better, more reliable information, as well as durability, rather than a sudden increase in conflict intensity. ${ }^{23}$

the control group react to the number of asylum-seekers from Syria. While this possibility exists, we deem it less likely in the short term. Also, when we study the development of asylum-seekers in the control group, pre- and post-policy, the trend stays remarkably stable over the relevant time frame (see Figure 3).

${ }^{21}$ For more information on this database, see De Haas et al. (2015).

${ }^{22} \mathrm{An}$ exemption is a German ad-hoc resettlement program. However, this program was small, launched already during the spring, and did not change the situation for Syrians fleeing to Germany.

${ }^{23}$ It should be noted that the first confirmed attacks involving use of chemical weapons 
Last, it is known that migration is cyclical over the year. In general, fewer people migrate over the winter than in the summer. Should the reform happen at the same time as a "high season", estimates can be inflated. In our case, the problem is likely the opposite. Migration tends to rise during spring and summer, while the Swedish reform took place in the beginning of the fall. We do, however, address seasonality in our regression estimates. ${ }^{24}$ We will also include a placebo test that conditions on the weekly change in asylum-seekers over 2012 (see Table C.1 in the Appendix, section C).

\section{Results}

The following section provides the results of the paper. First, we provide the baseline estimates showing a clear effect in the short-term on the weekly number of asylum-seekers to Sweden. We furthermore discuss the long term results and continue with a section on the European dimension, in which we provide suggestive evidence of the importance of the constrained Swedish bureaucracy. We end with a discussion on the changing characteristics of the Syrian refugees in Sweden.

\subsection{Baseline estimates - did the policy increase asylum ap- plications to Sweden?}

We start by plotting the weekly number of asylum-seekers in 2013 (Figure 3). The plot includes two predicted trends on both sides of the intervention line (time of policy change). As evident from the figure, there is a clear jump in the number of asylum-seekers at the intervention line. The jump peaks in the second week of September, after which the trend slowly begins to move downwards again. Only by studying the graphical evidence, we can hence conclude that there is a substantial effect already within the first week.

took place the weeks (three incidents) and months (two incidents) before the policy change (The UN-mission only investigated attacks from April to November 2013). However, there are a large number of unconfirmed attacks with alleged use of chemical weapons in 2012 and 2013. For a detailed description of the attacks involving chemical weapons see UNreport (A/68/663 S/2013/735) available at: https://undocs.org/A/68/663.

${ }^{24}$ Specifically, to address this issue, we use data for all Syrian applications from 2010 to 2015. Based on this period, we put a weight on each month, using so-called fourier series. Fourier series is a concept in trigonometry, where each observation is weighed on the interval of $(-1,1)$. If part of the estimate is due to seasonal changes, this should be picked up by using this model. We present regression results including fourier terms in the Appendix, in section B, in Table B.1. 
Figure 3: Plotting the number of asylum-seekers from Syria to Sweden weekly (including control group countries)

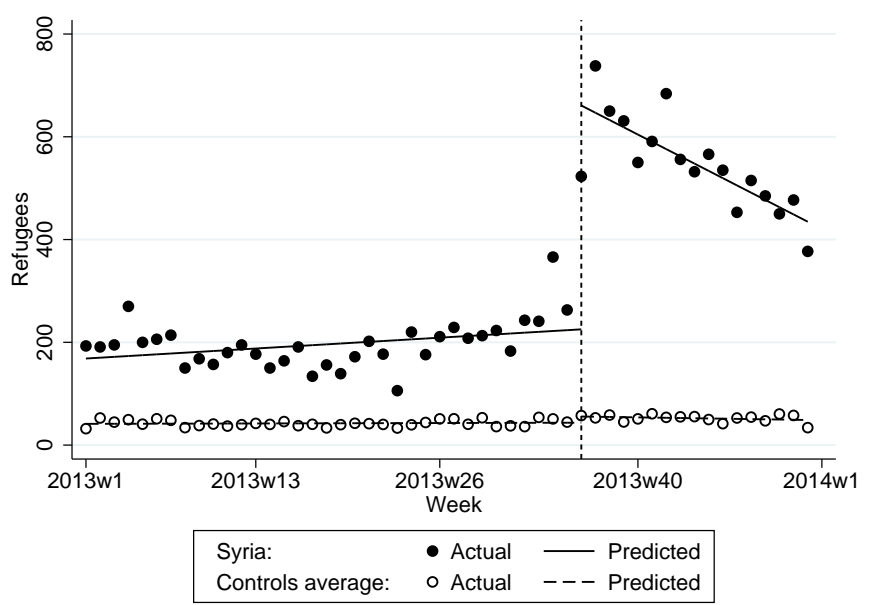

Note: The number of asylum applications to Sweden from Syrian citizens, per week. Results starting from the first week of 2013 until the first week of 2014 . The control group consists of the average number of asylum-seekers from the 4 largest sending countries besides Syria: Afghanistan, Eritrea, Iraq and Somalia. The predicted lines are based on the model specified in Equation 2.

Source: Swedish Migration Agency.

Moving on to the estimations, a single group interrupted time-series regression (Equation 1) including an interaction term gives an estimate of 435 more Syrians per week. Given that the weekly average of Syrian asylumseekers before the reform (during 2013) was around 200 individuals, the effect is very large. Note, however, that the model used assumes a linear set-up. We might instead want to measure the effect, conditional on a nonlinear trend before and after the policy change. This can easily be done by adding a second-order polynomial to the model. When adding the non-linear terms, the relevant estimate drops to 330 Syrians more per week, which is also a very large effect. The size of the coefficient implies that more than 5000 additional Syrian asylum-seekers arrived over a 16 week period, who would not have arrived given no policy change. ${ }^{25}$

In line with Equation 2, we further add a plot of a control group, consisting of the average number of asylum-seekers from Somalia, Iraq, Eritrea, and Afghanistan. These countries represent the four largest source countries

\footnotetext{
${ }^{25}$ We have also estimated the model including a third-degree polynomial, which gives us a very similar estimate as to when using only a second-degree polynomial. Results are available upon request.
} 
during the period, besides Syria. This plot clearly shows strong stability over the entire period, with no apparent jump over the intervention line in 2013. Since very little happened, interrupted time-series regressions based on the multiple group design in Equation 2, practically replicate the results of the baseline regression. These estimates are all found in the Appendix, in section B, Table B.1. ${ }^{26}$

\section{The long-term}

We also plot the weekly number of asylum-seekers against a longer period; beginning with the first week of 2013 and ending with the twenty-sixth week of 2015. Given the extreme developments in migration patterns during the second half of 2015, with a massive influx of refugees traveling from Turkey to Greece, the breakdown of the Dublin regulation, and a general upsurge in asylum claims in Europe,${ }^{27}$ we argue that the inclusion of any additional period would tell us very little with regards to the effect of permanent residence permits.

Figure 4 mirrors the results reported in Figure 3: there is a clear jump in the number of asylum-seekers at the intervention line followed by a negative trend in the inflow of Syrian asylum-seekers. The jump is also captured in the estimates provided by our interrupted time-series regressions, seen in Table B.2 (in the Appendix, section B). However, in the discussion about the long-term effects, it is important to have the previously described methodological drawbacks in mind, suggesting an associative rather than a causal relationship.

Nevertheless, Figure 4 points to two main long-term developments following the policy change, which allows us to draw some conclusions. Firstly, we can most likely reject a cumulative long-term increase in the trend of Syrian asylum-seekers following the policy change. Instead, we see a negative trend

\footnotetext{
${ }^{26}$ In the Appendix, in section $\mathrm{C}$, we also include placebo checks using the number of asylum-seekers who arrived in 2012 (Table C.1) and regressions controlling for an estimated number of verified deaths in Syria per month (Table C.2). The estimates are robust to both these specifications.

${ }^{27}$ According to Düvell (2018), approximately 851,319 individuals arrived in Greece after crossing the Aegean Sea from Turkey in 2015. The migration flows between the countries increased dramatically over the year, starting from 1,964 individuals in January to 211,663 in October. Also, statistics from the UNHCR (2019) show that the monthly average in the number of asylum claims made from January 2012 to June 2015 in the EU was 6,362. This number can be compared to the monthly average in the latter part of the year, from July to December, which was 47,682 .
} 
Figure 4: Plotting the weekly number of asylum-seekers from Syria to Sweden from January 2013 to June 2015 (including control group countries)

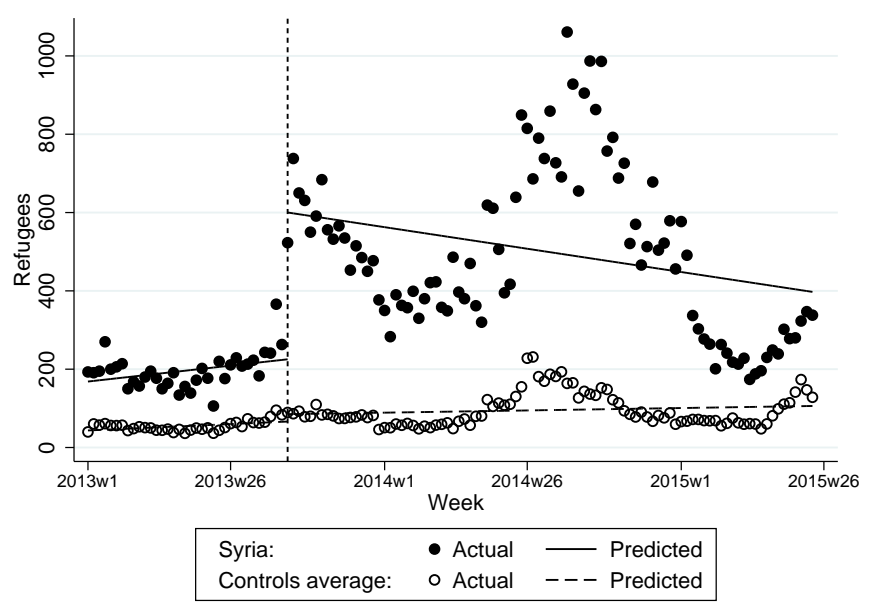

Note: The number of asylum applications to Sweden from Syrian citizens, per week. Results starting from the first week of 2013 until the twenty-sixth week of 2015 (until the 28th of June 2015). The control group consists of the average number of asylumseekers from the 4 largest sending countries besides Syria: Afghanistan, Eritrea, Iraq and Somalia. The predicted lines are based on the model specified in Equation 2.

Source: Swedish Migration Agency.

in the number of Syrian asylum-seekers over the period. This is surprising given that no other European country followed the liberal regulations implemented in Sweden, and that an increasing number of Syrians were displaced over the period. Secondly, the increase in the number of Syrian asylumseekers and the following level change remains for a substantial number of weeks, well into 2014, before the trend returns to an assumed pre-policy level. We return to the negative long-term trend and its potential causes more in detail in section 5.2 below.

\subsection{The European context}

Having shown that the policy change affected the number of asylum applications from Syria, we continue with how the change affected the distribution of asylum-seekers in Europe. Did all Syrians coming to Europe now opt for Sweden? Or did the larger flow of asylum-seekers go elsewhere?

To look into this we use monthly data from Eurostat, and compare the share of asylum applications into Europe. To keep the comparison relevant, we restrict ourselves to plausible substitute countries. To pick these out, we 
Figure 5: Share of European asylum-seekers going to Germany or Sweden

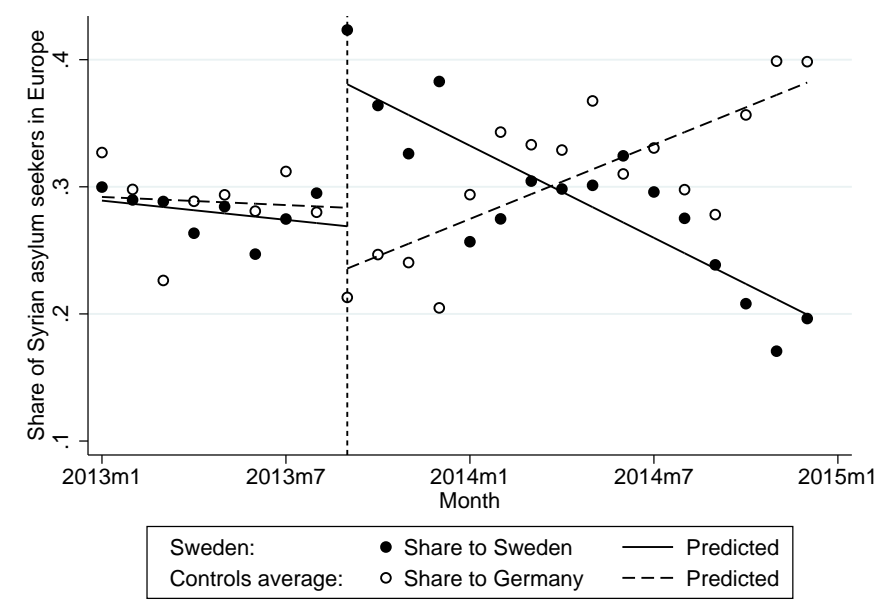

Note: Monthly share of Syrians seeking asylum in Europe, going to Germany or Sweden.

Source: Eurostat.

use two main factors: 1) the size of the Syrian enclave in the destination country and 2) the distance from Sweden. Both these factors have proven important in several cross country estimations. By using UNHR data, we find that Germany and the Netherlands are the only countries within a reasonable distance, which also received a sizable share of Syrian refugees 1990-2010. Given that Germany and Sweden cover the majority of the applications from Syria after 2013, accounting for more than $60 \%$ of the total number of applications in the EU, we limit our comparison to these two countries. ${ }^{28}$

In Figure 5, we plot the share of Syrian applications on the European level for Sweden and Germany from the start of 2013 to the end of 2014. We use monthly estimates since Eurostat lacks data on weekly level. ${ }^{29}$ As can be seen, the share of applications is relatively stable and at an equal level between the countries, at about $30 \%$ each, in the months leading up to the policy change.

In September 2013, and the following months, the trends change drasti-

\footnotetext{
${ }^{28}$ For details, see Appendix, section D, in Figure D.1 and Table D.1. Note that we have also looked into the development in the Netherlands. The share of Syrians choosing Netherlands, however, stays fairly stable over the period 2013-2014.

${ }^{29}$ We start at 2013 for illustrative purposes. The number of asylum-seekers was much fewer in the beginning of 2012, making the measure of shares much less reliable with a much higher variance.
} 
cally when, reflecting our baseline results, migration flows turn to Sweden over Germany. The trend lasts for about four months before it, again, harmonizes with the German level and then drops in the summer of 2014. Thus, although the Swedish change of policy had an intense and direct effect on the European distribution of Syrian asylum-seekers, the effect was rather limited in a longer time frame. As suggested in Section 5.1, it seems that the effect on the European distribution of Syrian asylum-seekers was significant in the short run, as an increasing number of refugees came to Sweden that otherwise would have applied for asylum in Germany. The swift change in the shares between the two countries suggests that these were mainly asylum migrants who had already left Syria, with a relatively short distance to travel to Germany or Sweden.

\section{Constraints on the Swedish bureaucracy}

The diminishing European share of Syrian asylum-seekers opting for Sweden is a puzzling trend. The trend is particularly interesting given that Sweden kept permanent residence permits through the entire period contrary to, for instance, Germany. Although it is difficult to point to a single factor causing this trend, we argue that one major explanation is the decreased efficiency and the culminating constrains put on the Swedish bureaucracy handling asylum cases.

As a consequence of the sudden inflow of Syrian asylum-seekers, the effectiveness of the Swedish bureaucracy handling applications for asylum dropped drastically. At the time of the policy change, the average processing time for the SMA to settle one Syrian claim was 87 days. A year later, the processing time had risen to an average of 123 days, and in June 2015, it had increased to 265 days. From the perspective of the individual applicant, the processing time is of utmost importance as family reunification is possible only after a residence permit has been granted. The efficiency of the Swedish bureaucracy can be further compared to the development in Germany. In 2013, the SMA processed one Syrian claim 54 days faster compared to the German migration agency. However, as the processing time in Sweden increased, the relative difference between the countries gradually culminated in favor of Germany over 2014, before it sky-rocketed in 2015 when one claim was processed 167 days faster in the German system. ${ }^{30}$

\footnotetext{
${ }^{30}$ Note that this refers to the time until a residence permit was granted. Hence,
} 
Figure 6: Plotting the monthly processing time and the share of Syrian asylum-seekers applying in other EU member states

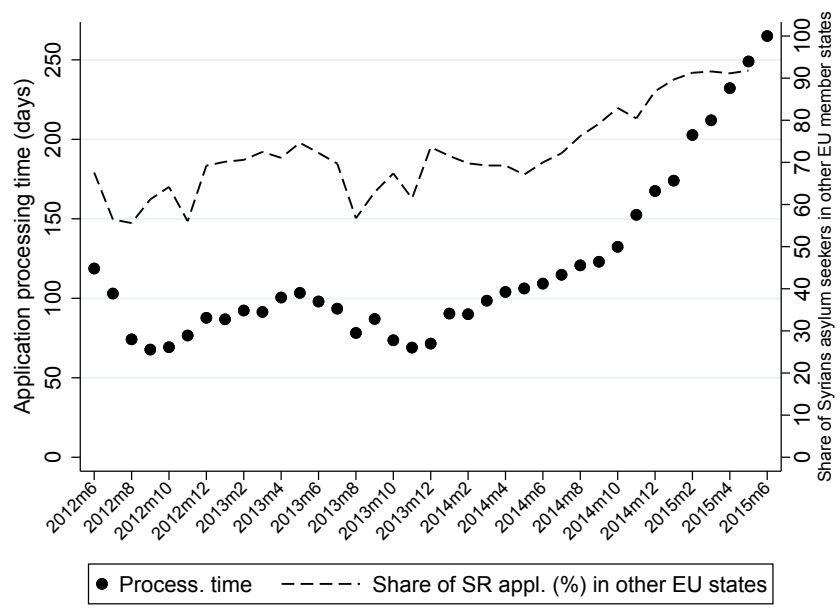

Note: Monthly processing time in Syrian applications measured in days (right axis). European share of Syrian asylum-seekers not applying in Sweden in $\mathrm{t}+1$ (left axis). Graphs stars in June 2012 and ends in June 2015.

Source: Swedish Migration Agency.

In order to test the relationship between processing time and the number of asylum-seekers, we collected data on the processing time of residence permit decisions from the Swedish Migration Agency. The steady increase over time is demonstrated in Figure 6, which plots the monthly average of the number of days until a residence permit decision, and the share of Syrian asylum-seekers in Europe not choosing Sweden in the following month. The figure indicates that there is a strong correlation between asylum applications in other European member-states and the increase in processing times in Sweden.

We extend this analysis further by regressing the log of the monthly European share of Syrian asylum-seekers coming to Sweden in $t$ on the log of the mean application processing time for a decision taken in $t-1$. These results are seen in Table 1, and show a clear negative elasticity. Even when controlling for the time trend and a second-order polynomial, our results suggest a one percent increase in processing time is associated with a 0.82

someone given a residence permit in $2015 \mathrm{had}$, in average, waited 167 days longer in Sweden than in Germany. Data regarding processing time in Sweden is from the SMA and data regarding processing time in Germany is from the Asylum in Europe, see http://www.asylumineurope.org/reports/country/germany/ asylum-procedure/procedures/regular-procedure. 
Table 1: Effect of processing time in Sweden on the share of Syrian asylum-seekers coming to Sweden

\begin{tabular}{|c|c|c|}
\hline & $(1)$ & $(2)$ \\
\hline $\log ($ mean processing time $)$ & $\begin{array}{c}-1.29 * * * \\
(0.11)\end{array}$ & $\begin{array}{c}-0.82^{* * *} \\
(0.25)\end{array}$ \\
\hline Month & & $\begin{array}{c}0.01 \\
(0.02)\end{array}$ \\
\hline Month $^{2}$ & & $\begin{array}{l}-0.00 \\
(0.00)\end{array}$ \\
\hline Observations & 36 & 36 \\
\hline \multicolumn{3}{|c|}{$\begin{array}{l}\text { Notes: Monthly data. Column (1) regresses the log of } \\
\text { the monthly European share of Syrian asylum-seekers } \\
\text { coming to Sweden in } t \text { on the log of the mean application } \\
\text { processing time for a decision taken in } t-1 \text {. Column }(2) \\
\text { includes covariates }\left(\text { Month, Month }{ }^{2} \text {. Standard errors in }\right. \\
\text { parentheses } * * *=\mathrm{p}<0.01 ; * *=\mathrm{p}<0.05 ;{ }^{*}=\mathrm{p}<0.1 \text {. } \\
\text { Source: Swedish Migration Agency. }\end{array}$} \\
\hline
\end{tabular}

percent decrease in the share of Syrians opting for Sweden. ${ }^{31}$

All in all, we argue that the sudden inflow of Syrian asylum-seekers drastically affected the efficiency to handle Syrian claims for asylum in particular. This trend, combined with the situation in the reception system, significantly postponed access to one of the major benefits of the policy change, family reunification, and should, therefore, be considered as the main explanation for the trend reversal.

Note that, although we believe processing time to be the key factor, we cannot completely rule out a second explanation: the effect of a German labor market liberalization. While there were no major changes in German residence permit policy during this period (see DEMIG policy database), the country did liberalize the access to the labor market. In May of 2014, the Bundestag decided that asylum-seekers would be allowed to apply for a work permit already within three months, instead of the previous nine. The new policy was implemented during the fall of 2014 and led to a potentially

\footnotetext{
${ }^{31}$ In relation to the increased constraints put on the Swedish bureaucracy, political and public debate about capacities, strategies and local refugee reception intensified during this time period. These signals may also have affected asylum-seekers that otherwise would have come to Sweden. However, the official signals sent out as late as December 2015 by authorities remained neutral. For example, the Swedish Civil Contingencies Agency announced that there was no substance in any claims of a "system collapse" in the Swedish reception system (Ericson, 2018).
} 
faster access to the labor market for all asylum-seekers, including Syrians. ${ }^{32}$ That said, one key feature speaks against the German labor market as the main driver of the change in asylum trends: asylum-seekers in Sweden could already work during the asylum process; regardless of time spent in the country. Hence, at least from a legal perspective, the German labor market was not more accessible for asylum-seekers. ${ }^{33}$

\subsection{Did the policy affect the characteristics of the migrants?}

As a policy-maker, it is naturally of great interest to know, not only the expected number of refugees, but also if a change to permanent residence permits attracts individuals with certain traits. As a last follow-up question, we therefore investigate the characteristics among the arriving Syrian refugees before and after the policy.

For this task, we make use of a full population database (GEOSWEDEN) holding individual register data. The database includes information on demographics, labor market status, education, the reason for immigration, the month of residence permit, and much more. Importantly, however, we do not have access to the date of the actual asylum application, which means we have to approximate a treatment and a control group.

To construct a treatment and control group, we first select all Syrian refugees who received their residence permit during 2013, up until September. Since the policy change took place in September, individuals in this group could not have selected Sweden based on the new, more liberal rules, and will be sorted as before the policy. Second, data from the SMA show that $98 \%$ of the Syrian asylum-seekers who got their residence permits in March 2014 applied for asylum after the policy change. We therefore sort the Syrian-born individuals who got their residence permits in March 2014 and onward as arriving after the policy. The database ends in December 2014; hence we cannot include any cases after this.

We start by considering the level of education. Table 2 compares the

\footnotetext{
${ }^{32}$ For more information see, https://www . bundesregierung.de/Content/EN/Artikel/ 2014/04/2014-04-30-sichere-herkunftstaaten-arbeitsmarkt_en.html.

${ }^{33}$ In practice, the asylum-seeker in Sweden had to apply for an exception from the rule that working in Sweden requires a work permit. This exception was granted under a set of specific conditions in a) the submission of proper identification papers, b) having a claim considered in Sweden, and c) having solid reasons for that claim, i.e., not being subject to refusal of entry with immediate effect. These conditions were generally not an issue for a Syrian asylum-seeker at the time.
} 
Table 2: Share of Syrian individuals with different levels of education before and after the policy change

\begin{tabular}{lccc}
\hline \hline & $(1)$ & $(2)$ & $(3)$ \\
& Before & After & Difference \\
\cline { 2 - 4 } University educated & 0.359 & 0.404 & $0.045^{* * *}$ \\
High school educ & 0.179 & 0.191 & $0.012^{*}$ \\
Up to maximum of 9 years education & 0.372 & 0.335 & $-0.037^{* * *}$ \\
Unknown or no education & 0.0893 & 0.0698 & $-0.019^{* * *}$ \\
Observations & 5,174 & 10,351 & \\
\hline \hline
\end{tabular}

Notes: Share of university educated, high school educated, with nine years of education and no education among adult Syrian refugees who arrived before or after the policy reform. See text for more details on how the before and after is created.

Source: GeoSweden.

situation before and after the policy, using three levels of education: The most educated group, including people with any post-high school education; a mid-tier group with high-school or an equivalent level of training and a last group which includes those with no more than nine years of schooling.

Table 2 shows that the policy attracted more highly educated individuals. The increase is significant and represents an increase of close to five percentage points.

We interpret the increase primarily as a result of the difference in resources. The average highly educated has more economic resources, as well as a better access to information than those with less education. The former group can therefore learn about the change faster, but also act on the information quicker. ${ }^{34}$

In Table 3, we continue by comparing demographic characteristics. As is evident from the table, several traits changed. First, there is a clear jump in the share of men. The pre-change share of 58 percent increased to 68 percent, which in absolute numbers represent an increase of around 4000 men. Second, while the mean age did not change significantly, comparisons between age-groups reveal that younger adults came in greater numbers, while the share of children decreased. Third, we see a big drop in the share of individuals who arrived with a household member. ${ }^{35}$ Before the policy

\footnotetext{
${ }^{34}$ Note that the resource story would suggest that the share of highly educated among the Syrian refugees was especially large just after the policy change. This is consistent with what we observe in the data: A majority of the Syrian refugees who were given a residence permit in Jan-March in 2014 were highly educated, a share which is dropping the following months.

${ }^{35} \mathrm{~A}$ household member in this case includes a spouse or a child/parent.
} 
Table 3: Demographic characteristics of those arriving before and after the policy change

\begin{tabular}{lccc}
\hline \hline & \multicolumn{3}{c}{ FULL POPULATION } \\
& $(1)$ & $(2)$ & $(3)$ \\
Men & Before & After & Difference \\
\cline { 2 - 4 } Age & 0.578 & 0.684 & $0.106^{* * *}$ \\
Children in Sweden & 28.279 & 28.614 & 0.336 \\
Arrived with a family member & 0.315 & 0.244 & $-0.071^{* * *}$ \\
Children (< 18) & 0.619 & 0.444 & $-0.176^{* * *}$ \\
Age between 18 and 35 & 0.323 & 0.270 & $-0.053^{* * *}$ \\
Age between 34 and 60 & 0.341 & 0.389 & $0.048^{* * *}$ \\
Observations & 0.278 & 0.311 & $0.033^{* * *}$ \\
\hline \hline & 7,640 & 14,172 & \\
\hline & \multicolumn{3}{c}{ ADULTS } \\
Men & $(1)$ & $(2)$ & $(3)$ \\
Age & Before & After & Difference \\
\cline { 2 - 4 } Children in Sweden & 0.607 & 0.725 & $0.118^{* * *}$ \\
Arrived with a family member & 37.617 & 35.735 & $-1.883^{* * *}$ \\
Married & 0.402 & 0.288 & $-0.114^{* * *}$ \\
Age between 18 and 35 & 0.474 & 0.301 & $-0.173^{* * *}$ \\
Age between 34 and 60 & 0.590 & 0.614 & $0.024^{* * *}$ \\
Observations & 0.411 & 0.426 & $0.028^{* * *}$ \\
\hline \hline
\end{tabular}

Notes: Individual characteristics for asylum-seekers arriving from Syria who got a residence permit in Sweden January-September 2013 (column 1), and residence permit between March 2014 and December 2014 (column 2). Upper panel shows the full population. arrived with Family shows the share who had a household member who also arrived as a refugee during the period in question. The lower panel shows result only for adults $(>18) .{ }^{* * *}=\mathrm{p}<0.01 ;{ }^{* *}=\mathrm{p}<0.05 ;^{*}=\mathrm{p}<0.1$. Source: GeoSweden.

change, more than 60 percent of the permits were given to individuals, who arrived with a household member. This number dropped to a minority of 44 percent after the reform.

To complement, we add a comparison using only individuals older than 18. The pattern is similar: after the policy we see a larger share of men and a lower share of individuals with a household member. A likely story for these changes in characteristics is the possibility of family reunification. Before the policy change, asylum-seekers coming from Syria generally received temporary residence permits without the possibility of family reunification. Many families may in this case have chosen to go together, or not at all. The journey as an asylum-seeker to Europe is known to be risky, and it is 
likely even more risky for children. Therefore, given family reunification as an option, it is possible to send only one family member, who can thereafter apply for family reunification in Sweden. Our results in Table 3 show a picture consistent with this story, and that it was mostly the men who migrated before the rest of the family.

\section{Family spillover effects}

The decrease of individuals arriving with a family brings up an important last point, which is the family multiplier. Given that more individuals after the policy change arrived alone, we expect an increase in family reunification cases after the change. This is also detectable in data from the Migration Agency. In Figure 7, we plot the monthly number of new family reunification applications, as a share of permanent residence permits given. The figure suggests that the share of applications increased in the beginning of 2014, and after this remains fairly stable over both 2014 and 2015. Note that the effect does not happen immediately after the policy change. This is, however, to be expected, given that the average newly arrived asylumseeker will have to wait a few months for a residence permit. Not until after the decision regarding the residency status, can he or she apply for reunification. As stated above, almost all residence permits granted (98\%) were given to Syrians that applied after the policy change in March 2014. The growth in family reunification applications follows the same gradual pattern of increase.

To put a number on the increase, we now make the assumption that a majority of those who arrived in September 2013, had to wait at least until January for a decision on residence permit. We then apply the interrupted time-series approach and treat the first month of January in 2014 as a cut-off. Performing this analysis leaves us with the interpretation that the change in permanent residence permits led to a 25 -percentage point increase in the share applying for family reunification. ${ }^{36}$

The change in family reunification applications highlights two additional trends following the policy change. First, it is clear that the increase in

\footnotetext{
${ }^{36} \mathrm{It}$ is noticeable that this figure gives the number of applications as a share of permanent residence permits. In other words, all individuals in the comparison were eligible for family reunification. Note also that individuals arriving as family reunification cases are not counted as asylum seekers, hence we would not expect any mechanical increase in the number of asylum seekers seen in Table 4.
} 
Figure 7: Plotting the number of family reunification applications as share of permanent residence permits given to Syrian nationals during 2012-2015

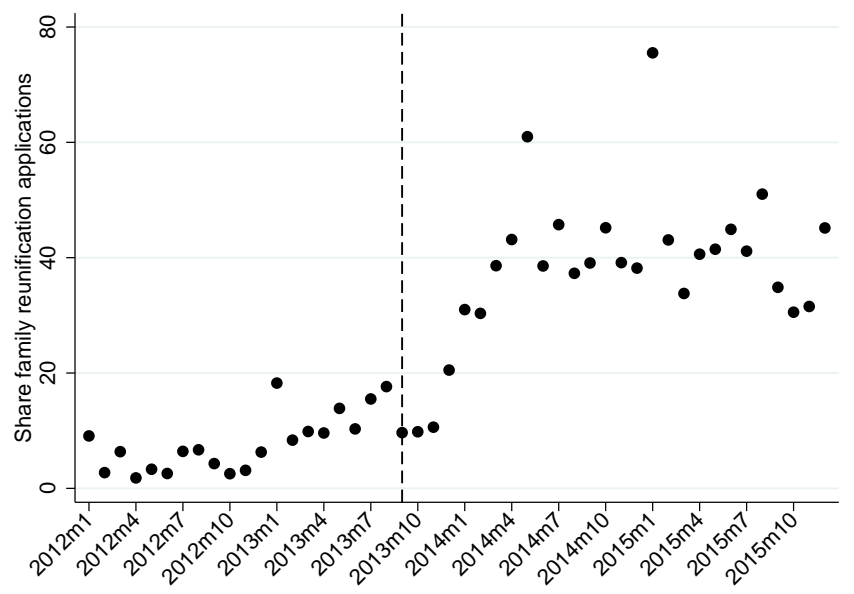

Note: The number of new family reunification applications to the Swedish migration agency per month, divided by the number of permanent residence permits given.

Source: Swedish Migration Agency.

asylum-seekers cannot be confined to the baseline comparison in Figure 3. The baseline results showed that 330 more Syrians per week arrived due to the policy, or aggregated, 5000 more over the course of the 16 weeks following the policy change. Now, using the results from Figure 7, we assume 25 percent more applications for family reunification due to the new policy. We can, therefore, expect a family multiplier effect of approximately 3750 additional individuals. In other words, the family multiplier is almost as big as the baseline effect in itself. ${ }^{37}$ Second, as is demonstrated by Figure 7, the policy change established a new level of family reunification applications, which remained over 2014 and 2015. It is therefore clear that the effect of permanent residence permits goes beyond the short term effect, with significant reunification effects in the long run.

\section{Conclusion}

In this study, we have set out to estimate the effect of a policy change on the number of Syrian asylum-seekers coming to Sweden in order to learn more

\footnotetext{
${ }^{37}$ Based a median Syrian family of 4 individuals, which is calculated using the sample of Syrians arriving in 2013 and 2014.
} 
about how asylum-seekers respond to policy changes. To this point, previous studies have largely been divided into two categories of quantitative and qualitative research, whereas the former points to the importance of varying push and pull factors, and the latter often argues that asylum-seekers, to a large extent, are unaware of the characteristics of the host destinations they end up in. Although these studies provide valuable insights, it is still essential to learn more about how destination country policies cause changes in migration flows, how fast these changes affect the distribution of migrants, and if migrants with certain traits are especially affected.

The approach taken in this paper has been to estimate the effect of a sudden Swedish policy change in September 2013. The change meant that all Syrian asylum-seekers would be granted permanent rather than temporary residence permits. By using an interrupted time-series design, we studied the effect of the change on the number of Syrian asylum-seekers to Sweden. We reach three main conclusions.

First, the policy change had a clear and direct effect on the number of Syrian asylum-seekers coming to Sweden. The weekly data gives an estimate of at least 330 more Syrians per week within 2013, after the policy change, with a significant jump already within the first week after the policy was declared. Given that the average weekly number of asylum-seekers before the reform was around 200, the effect should be seen as substantial. This effect is mirrored in our analysis of the European distribution of Syrian asylumseekers which suggests that Sweden became the major host-destination in Europe for Syrian asylum-seekers instantly after the policy change and in the following months. Interestingly, we see a comparable decline in the inflow of migrants to the other main European destination for Syrians asylumseekers, Germany, as a direct consequence of the policy change suggesting that a large number of refugees selected Sweden over Germany at the time. The results hence support a view that many Syrian asylum-seekers were informed about policy changes. The causal effect we provide complements, and are in line with, the associative results found in cross-country studies, such as Neumayer (2004); Thielemann (2006); Keogh (2013); Hatton (2009, 2016) and Brekke et al. (2017).

Second, we conclude that the policy change had some interesting effects on the composition of Syrian asylum-seekers coming to Sweden. We conclude that the share of households arriving together decreased as a response to the 
policy. Given the nature of the reform, enabling family reunification, these results are logical as one individual (most often men) could take the risky trip alone, and when in Sweden, apply for permits for their family members at a later stage. We also note that these results are valid in the long run. The policy change seems to have established a new level of applications for family reunification, which remained over the entire period studied. These results contrast somewhat to Hatton (2009), who finds clear policy effects from border polices and changes in policies regarding the asylum application, but not from changes in welfare policy. The results are further in line with theories emphasizing the household as the decision unit (Massey and Garcia, 1987; Massey et al., 1993).

Third, a few months after the policy change, the migration flows settle and Germany becomes the primary destination for refugees in Europe. We suggest that the decreasing share of asylum-seekers coming to Sweden may have been caused mainly by constraints put on the Swedish bureaucracy after the policy change, tripling the time for handling applications made by Syrian citizens. We give suggestive evidence of this, showing a clear negative association between processing times per month, and the share of Syrian asylum-seekers coming to Sweden.

Given our conclusion, that asylum-seekers do react to policy changes, it is crucial to discuss the generalizability of these results. One important aspect of this is how we should categorize the investigated policy in terms of impact. Should it be considered as having a higher or lower impact compared to other similar policy changes? In this regard, we assume that there are a few circumstances that make the impact of the policy change particularly high. Firstly, at the time of the policy change, Syrian refugees were the largest displaced group in the world. There was also a large group of Syrians already settled in Sweden, which may have increased the attractiveness of the country. Furthermore, the income of Syrian citizens was relatively high compared to other groups of refugees, which may have made Syrians more mobile. Taken together, these aspects suggest that, although there is a clear effect of the policy change, the results reported here should be considered as an upper bound.

The conclusions made in this paper points to potential follow-up studies. First, with a fairly strong agreement among researchers on the importance of push factors as well as fixed pull factors (geographical distance, language, 
colonial ties) in understanding the flows of asylum-seekers, the effects of policy is still a debated arena. Studies tracking specific changes in singular countries are, we believe, a fruitful way forward. Also, the results of this study have suggested some temporary and some long term effects. Following these results, it is important to increase understanding of which policy types that might create temporary and more long term effects on migration trends. Last, from a broader perspective, the study highlights the inter-dependence between states where even minor changes in one nation may have significant implications in others. Future studies will, therefore, do well to study spillover effects.

\section{References}

Balcilar, M. And J. Nugent (forthcoming): "The Migration of Fear: An Analysis of Migration Choices of Syrian Refugees," The Quarterly Review of Economics and Finance.

Bernal, J. L., S. Cummins, and A. Gasparrini (2017): "Interrupted Time Series Regression for the Evaluation of Public Health Interventions: a Tutorial," International Journal of Epidemiology, 46, 348-355.

Bratu, C., M. Dahlberg, M. Engdahl, and T. Nikolka (2018): "Spillover Effects of Stricter Immigration Policies," IFAU Working Paper 2018:13, 1-21.

Brekke, J.-P., M. Røed, And P. Schøne (2017): "Reduction or Deflection? The Effect of Asylum Policy on Interconnected Asylum Flows," Migration Studies, 5, 65-96.

Böcker, A. And T. Havinga (1998): Asylum Migration to the European Union: Patterns of Origin and Destination, Nijmegen: Institute for the Sociology of Law.

Castles, S., H. De HaAs, and M. J. Miller (2014): The Age of Migration, Palgrave Macmillan, 5 ed.

Collyer, M. (2005): "When Do Social Networks Fail to Explain Migration? Accounting for the Movement of Algerian Asylum-Seekers to the UK," Journal of Ethnic and Migration Studies, 31, 699-718. 
Crawley, H. (2010): Chance or Choice? Understanding Why Asylum Seekers Come to the UK, Refugee Council.

De HaAs, H., K. Natter, and S. Vezzoli (2015): "Conceptualizing and Measuring Migration Policy Change," Comparative Migration Studies, 3, $1-21$.

DüvelL, F. (2018): "The 'Great Migration'of summer 2015: analysing the assemblage of key drivers in Turkey," Journal of Ethnic and Migration Studies, 1-14.

Ericson, M. (2018): "SSweden Has Been Naïve": Nationalism, Protectionism and Securitisation in Response to the Refugee Crisis of 2015," Social Inclusion, 6, 95-102.

ESPON (2015): Territorial and Urban Aspects of Migration and Refugee Inflow, European Observation Network for Territorial Development and Cohesion (ESPON).

Freeman, G. P. (2004): "Immigrant Incorporation in Western Democracies," The International Migration Review, 38, 945-969.

Gilbert, A. And K. Koser (2006): "Coming to the UK: What do AsylumSeekers Know About the UK Before Arrival?" Journal of Ethnic and Migration Studies, 32, 1209-1225.

GÖRlach, J.-S. AND N. Motz (2017): "Refuge and refugee migration: How much of a pull factor are recognition rates," Unpublished Manuscript.

Hatton, T. J. (2009): "The Rise and Fall of Asylum: What Happened and Why?" The Economic Journal, 119, 183-213.

(2016): "Refugees, Asylum Seekers, and Policy in OECD Countries," American Economic Review, 106, 441-445.

Holzer, T., G. Schneider, And T. Widmer (2000): "The Impact of Legislative Deterrence Measures on the Number of Asylum Applications in Switzerland (1986-1995)," The International Migration Review, 11821216 .

JöRum, E. (2015): "Valet och vägen - en intervjustudie med nyanlända Syrier i Sverige," DELMI, 8. 
Keogh, G. (2013): "Modelling Asylum Migration Pull-Force Factors in the EU-15," The Economic and Social Review, 44, 371-399.

Linden, A. (2015): "Conducting Interrupted Time Series Analysis for Single and Multiple Group Comparisons," The Stata Journal, 15, 480-500.

Massey, D. S., J. Arango, G. Hugo, A. Kouaduci, A. Pellegrino, AND E. J. TAYLOR (1993): "Theories of International Migration: A Review and Appraisal," Population and Development Review, 19, 431-466.

Massey, D. S. and F. E. Garcia (1987): "The Social Process of International Migration," Science, 237, 733-738.

Mayblin, L. (2016): "Complexity Reduction and Policy Consensus: Asylum Seekers, the Right to Work, and the 'Pull Factor' Thesis in the UK Context," The British Journal of Politics and International Relations, 18, 812-828.

Moore, W. H. and S. M. Shellman (2007): "Whither Will They Go? A Global Study of Refugees' Destinations, 1965-1995," International Studies Quarterly, 51, 811-834.

Neumayer, E. (2004): "Asylum Destination Choice, What Makes Some West European Countries More Attractive Than Others?" European Union Politics, 5, 155-180.

Pione, J. M. (1979): Birds of Passage - Migrant Labor and Industrial Societies, Cambridge University Press.

RCI 1/2012 (2012): "Rättschefens instruktioner angående verkställigheter till Syrien," Swedish Migration Agency.

RCI 14/2012 (2012): "Rättsligt ställningstagande angående säkerhetssituationen i Syrien," Swedish Migration Agency.

RCI 14/2013 (2013): "Rättsligt ställningstagande angående säkerhetssituationen i Syrien," Swedish Migration Agency.

RCI 32/2011 (2011): "Rättsligt ställningstagande angående karaktären av den pågående konflikten i Syrien, bl.a. frågan om väpnad konflikt och andra svåra mottsättningar," Swedish Migration Agency. 
Sassen, S. (1996): Losing Control?: Sovereignty in an Age of Globalization, Columbia University Press.

(1998): "The De Facto Transnationalizing of Immigration Policy," in Challenge to the Nation-State: Immigration in Western Europe and the United States, ed. by C. Joppke, Oxford University Press.

Soysal, Y. N. (1994): Limits of Citizenship: Migrants and Postnational Membership in Europe, University of Chicago Press.

Thielemann, E. R. (2006): "The Effectiveness of Governments' Attempts to Control Unwanted Migration," in Immigration and the Transformation of Europe, ed. by C. A. Parsons and T. A. Smeeding, Cambridge Unversity Press, chap. 17, 442-472.

UNHCR (2016): "Global Trends - Forced Displacement in 2015," http: //www. unhcr.org/576408cd7.pdf, accessed January 8, 2018.

Zimmermann, K. F. (1996): "European Migration: Push and Pull," International Regional Science Review, 19, 95-128. 


\section{Appendix}

The Appendix holds the following information: First, the route from Syria to Europe in section A. Second, tables showing our interrupted time-series estimations in section B. Third, some robustness tests in section C. Fourth, we show some information on substitution between European countries regarding reception of Syrians in section D. Last, we shortly describe all databases used in this paper.

\section{A Routes to Europe}

As we state in section 3 , we cannot provide a time frame estimating the average time to travel to Europe from Syria. The time frame to travel to Europe heavily depends on the route chosen and where the individual was located when the policy was instated. In Figure A.1 we provide a map of the two main routes to Europe for Syrian asylum-seekers; the Central Mediterranean route and the Eastern Mediterranean route.

Figure A.1: The two main routes from Syria to Europe

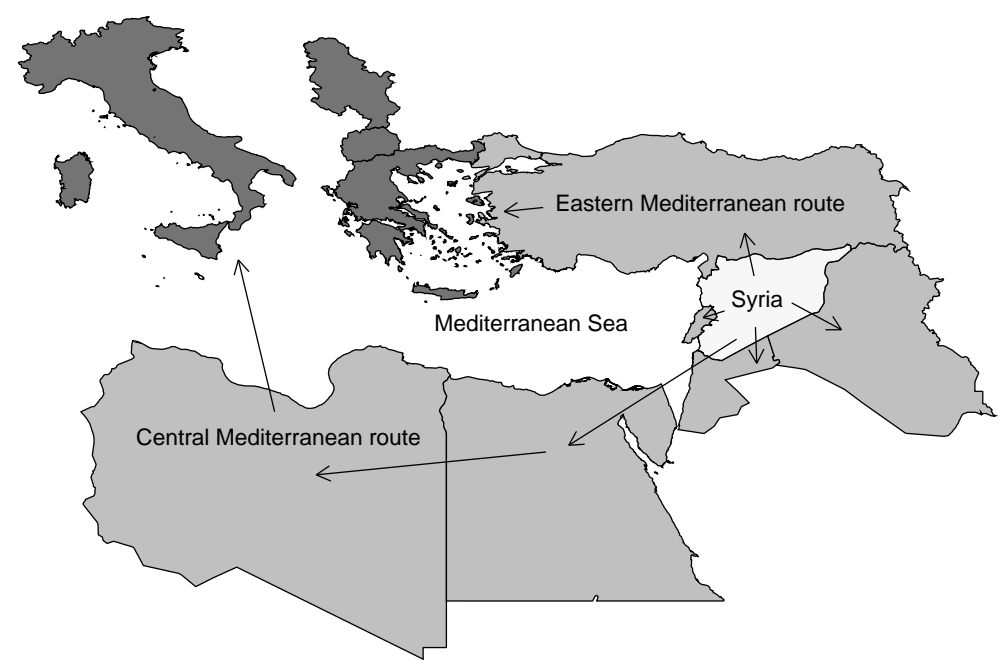

Note: The figure display the two main routes from Syria to Europe; the Central Mediterranean route and the Eastern Mediterranean route. The Central Mediterranean route goes from Libya to Malta and Italy. Between the years of 2010 - 2015 there were over 50,000 irregular border-crossings by Syrian citizens reported on this route. The Eastern Mediterranean route goes through Turkey - harboring almost 2 million Syrian refugees - to Greece. This route has over 60,000 irregular border-crossings by Syrian citizens between the years of 2010 and 2015.

Source: ESPON (2015) 


\section{B Regression tables}

Table B.1: Effect of permanent residence permit on the weekly number of asylum-seekers from Syria, over 2013

\begin{tabular}{lcccc}
\hline \hline & $\begin{array}{c}(1) \\
\text { Baseline }\end{array}$ & $\begin{array}{c}(2) \\
+ \text { fourier terms }\end{array}$ & $\begin{array}{c}(3) \\
\text { with control } \\
\text { group }\end{array}$ & $\begin{array}{c}(4) \\
\text { with non-linear } \\
\text { terms }\end{array}$ \\
\hline weeks & 1.622 & 1.659 & 0.657 & $-12.94^{*}$ \\
& $(1.046)$ & $(0.983)$ & $(0.410)$ & $(5.691)$ \\
reform & $435.6^{* * *}$ & $436.4^{* * *}$ & $411.1^{* * *}$ & $334.2^{* * *}$ \\
& $(40.71)$ & $(39.20)$ & $(42.93)$ & $(55.21)$ \\
reform*weeks & $-15.76^{* * *}$ & $-15.97^{* * *}$ & -2.063 & -3.495 \\
& $(2.955)$ & $(2.938)$ & $(1.461)$ & $(5.690)[1 \mathrm{em}]$ \\
\hline Observations & 52 & 52 & 260 & 260 \\
Adjusted $R^{2}$ & 0.924 & 0.918 & 0.918 & 0.927 \\
Model & ols & ols & ols & ols \\
\hline \hline
\end{tabular}

Notes: OLS regressions of the number of Syrian asylum-seekers to Sweden per week, in 2013, regressed on a dummy representing the change in policy, in the first week of September 2013 (reform), number of weeks into 2013 (weeks) and an interaction term. In column (1) we estimate the model in Equation 1, with weeks $=\beta_{1}$, reform $=\beta_{2}$ and reform $*$ weeks $=\beta_{3}$. The second column further adds fourier terms to adjust for seasonality. In column (3) we estimate the model from Equation 2. In the last column we add a second degree polynomial (see text for more info). ${ }^{* * *} \mathrm{p}<0.01,{ }^{* *} \mathrm{p}<0.05,{ }^{*} \mathrm{p}<0.1$. Newey West Standard errors adjusted for (1) lag in parentheses.

The adjustment for seasonality is done using fourier terms. These are created in three steps: First, we use monthly data. Second, we treat the year as a clock, giving each month a degree value from 30 (January) to 360 (December). Third, we take out fourier terms, which is done using the formula: $\cos \left(\right.$ degree $\left._{t} * \frac{\pi}{180}\right)$ and $\sin \left(\right.$ degree $\left._{t} * \frac{\pi}{180}\right)$, where degree $e_{t}$ represents the degree value allocated to each month $(t)$. The formula gives two variables in which each month is given a value on the interval of $[-1,1]$. 
Table B.2: Effect of permanent residence permit on the weekly number of asylum-seekers from Syria (January 2013 - June 2015)

\begin{tabular}{lcccc}
\hline \hline & $\begin{array}{c}(1) \\
\text { Baseline }\end{array}$ & $\begin{array}{c}(2) \\
+ \text { fourier terms }\end{array}$ & $\begin{array}{c}(3) \\
\text { with control } \\
\text { group }\end{array}$ & $\begin{array}{c}(4) \\
\text { with non-linear } \\
\text { terms }\end{array}$ \\
\hline weeks & 1.622 & 1.464 & $0.654^{*}$ & 48.42 \\
& $(0.869)$ & $(0.988)$ & $(0.304)$ & $(48.23)$ \\
reform & $373.5^{* * *}$ & $377.6^{* * *}$ & $356.6^{* * *}$ & $272.2^{* * *}$ \\
& $(34.64)$ & $(37.29)$ & $(9.577)$ & $(22.41)$ \\
reform*weeks & $-3.782^{* * *}$ & $-3.647^{* *}$ & -0.373 & -4.301 \\
& $(1.015)$ & $(1.101)$ & $(0.323)$ & $(3.790)$ \\
& & & $(35.94)$ & $(66.73)$ \\
\hline Observations & 130 & 130 & 650 & 650 \\
Adjusted $R^{2}$ & 0.396 & 0.379 & 0.660 & 0.708 \\
Model & ols & ols & ols & ols \\
\hline \hline
\end{tabular}

Notes: OLS regressions of the number of Syrian asylum-seekers to Sweden per week, January 2013 to June 2015, regressed on a dummy representing the change in policy, in the first week of September 2013 (reform), number of weeks (weeks) and an interaction term. In column (1) we estimate the model in Equation 1, with weeks $=\beta_{1}$, reform $=\beta_{2}$ and reform $*$ weeks $=\beta_{3}$. The second column further adds fourier terms to adjust for seasonality. In column (3) we estimate the model from Equation 2 . In the last column we add a second degree polynomial. ${ }^{* * *} \mathrm{p}<0.01,{ }^{* *} \mathrm{p}<0.05,{ }^{*} \mathrm{p}<0.1$. Newey West Standard errors adjusted for (1) lag in parentheses.

The adjustment for seasonality is done using fourier terms. These are created in three steps: First, we use monthly data. Second, we treat the year as a clock, giving each month a degree value from 30 (January) to 360 (December). Third, we take out fourier terms, which is done using the formula: $\cos \left(\right.$ degree $\left._{t} * \frac{\pi}{180}\right)$ and $\sin \left(\right.$ degree $\left._{t} * \frac{\pi}{180}\right)$, where degree $t$ represents the degree value allocated to each month $(t)$. The formula gives two variables in which each month is given a value on the interval of $[-1,1]$. 


\section{Robustness}

\section{C.1 Placebo}

As an additional robustness test, we perform a placebo analysis based on the weekly number of Syrian asylum-seekers in 2012. We do this in two steps:

First, in Figure C.1, we visually inspect the 2012 weekly development of Syrian asylum-seekers. As is shown in the graph, up until the cut-off in week 36, the trend is remarkably similar to that of 2013. The number of asylum-seekers remain stable and fairly low for the first quarter of the year, after which the frequency increases up until September. In the last quarter of the year the effect levels of. Most importantly, unlike in 2013, there is no distinguishable jump at the cut off.

Figure C.1: Plotting the number of asylum-seekers from Syria to Sweden during 2012 weekly

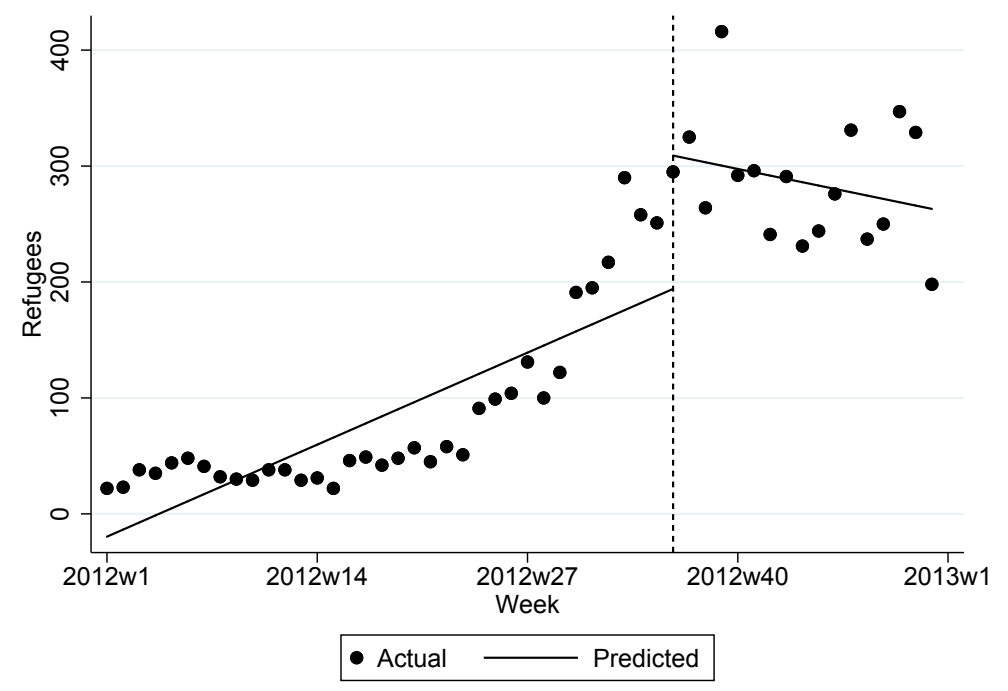

Note: The number of asylum applications to Sweden from Syrian citizens, per week. Results starting from the first until the last week of 2012. The predicted lines are based on the model specified in Equation 2.

Source: Swedish Migration Agency.

Second, we perform an interrupted time-series regression, including the development in 2012 as a control group. More specifically, we fit the following equation: 


$$
\begin{aligned}
& \text { \# asylumseeker } s_{t}=\beta_{0}^{P l}+\beta_{1}^{P l} T+\beta_{2}^{P l} \text { reform } \text { for }_{t}+\beta_{3}^{P l} \text { reform } \text { fo }_{t} T+ \\
& \beta_{4}^{P l} Z+\beta_{5}^{P l} Z * T+\beta_{6}^{P l} Z * \text { reform } \text { for }_{t}+\beta_{7}^{P l} Z * \text { reform } \text { f }_{t} * T+\varepsilon_{t}
\end{aligned}
$$

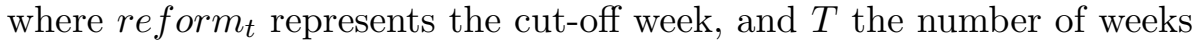
into the year. $Z$ is a dummy taking the value 1 for the treatment group, which includes Syrian asylum-seekers in 2013, and the value 0 for the control group, represented by Syrian asylum-seekers in 2012. The coefficient of interest is $\beta_{6}$, which provides a the effect of the reform on Syrian asylumseekers in 2013, given the effect in $2012 .{ }^{38}$

The coefficient of interest is seen in column 1 in Table C.1. According to the coefficient, the change caused 320 more Syrians per week to arrive in 2013. The effect hence remains strong, conditional on the seasonal developments the previous year. The effect is comparable to the effects seen in the non-linear version of the baseline model of Table B.1.

Table C.1: Estimate using Syrian inflow 2012 as control group (Equation 3)

\begin{tabular}{lc}
\hline \hline & $(1)$ \\
\hline Reform & $320.6^{* * *}$ \\
& $(52.78)$ \\
\hline Observations & 104 \\
\hline \hline${ }^{*} p<0.05,{ }^{* *} p<0.01,{ }^{* * *} p<0.001$
\end{tabular}

\section{C.2 Adding control for verified casualties}

Another legitimate objection to the identification strategy concerns the conflict in Syria. In Table C.2, we redo the estimation in Table B.1, column 4, but add a measure of the intensity of the conflict. The measure captures the verified number of casualties per month in Syria, and is collected by "humanitarian tracker" ${ }^{39}$ As can be noticed, neither adding the the number of verified deaths in the same month, nor a lagged version $(t-1)$ changes our estimate of the reform.

\footnotetext{
${ }^{38} \mathrm{Pl}$ stands for "placebo".

${ }^{39}$ Data from humanitarian tracker have for example been used in Balcilar and Nugent (forthcoming).
} 
Table C.2: Effect permanent residence permit on the weekly number of asylum-seekers from Syria, adding control for verified deaths in Syria per month

\begin{tabular}{lcc}
\hline \hline & $\begin{array}{c}(1) \\
\text { Control for } \\
\text { verified deaths in } t\end{array}$ & $\begin{array}{c}(2) \\
\text { Control for } \\
\text { verified deaths in } t-1\end{array}$ \\
\hline reform & $\begin{array}{c}337.0^{* * *} \\
(47.04)\end{array}$ & $322.6^{* * *}$ \\
& & $(47.72)$ \\
verified deaths Syria & 0.00617 & \\
(month=t) & $(0.009)$ & \\
& & -0.0107 \\
verified deaths Syria t-1 & & $(0.016)$ \\
(month=t-1) & 53 & 52 \\
\hline Observations & 0.944 & 0.945 \\
Adjusted $R^{2}$ & ols \\
model & & \\
\hline \hline Column $(1)$ and $(2)$ is based on the same model as in Table B.1, column 4. \\
Robust standard errors in parenthesis. \\
${ }^{*} p<0.05,{ }^{* *} p<0.01,{ }^{* * *} p<0.001$
\end{tabular}




\section{Country substitutability in Europe for Syrian asylum-seekers}

In section 5.2 we base our choice of substitution country (countries) on 1) distance and 2) the existence of a Syrian population in the country. For the latter, Table D.1 reports the yearly average in the number of received Syrians (granted asylum applications) among the top-ten hosts in Europe from 1990 to 2010. Column 2 further reports received Syrians per 1000 inhabitants. Figure D.1 visualizes the average in received Syrians per 1000 inhabitants over the same time period. Considering the existing ethnic enclaves of Syrians in Europe, Sweden and Germany constitute two similar cases that, in combination with close spatial proximity, must be argued to have high substitutability. The Netherlands and Denmark may also be considered as substitutes for Sweden.

Table D.1: Top ten hosts of Syrians refugees among the EU member-states between 1990-2010

\begin{tabular}{lcc}
\hline \hline Country & $\begin{array}{c}\text { Migrated Syrians } \\
\text { (annual average) }\end{array}$ & Per 1000 inh. \\
\hline Sweden & 2011 & 0,23 \\
Germany & 8962 & 0,11 \\
Netherlands & 1418 & 0,09 \\
Cyprus & 40 & 0,06 \\
Denmark & 200 & 0,04 \\
Austria & 177 & 0,02 \\
Malta & 8 & 0,02 \\
Belgium & 116 & 0,01 \\
Finland & 38 & 0,01 \\
Bulgaria & 49 & 0,01 \\
\hline \hline
\end{tabular}

Notes: Statistics on population size from $\mathrm{Eu}-$ rostat (2019) and statistics on accepted Syrian refugees from UNHCR (2019) 
Figure D.1: Accepted Syrian refugees per 1000 inhabitants in the EU member-states from 1990-2010

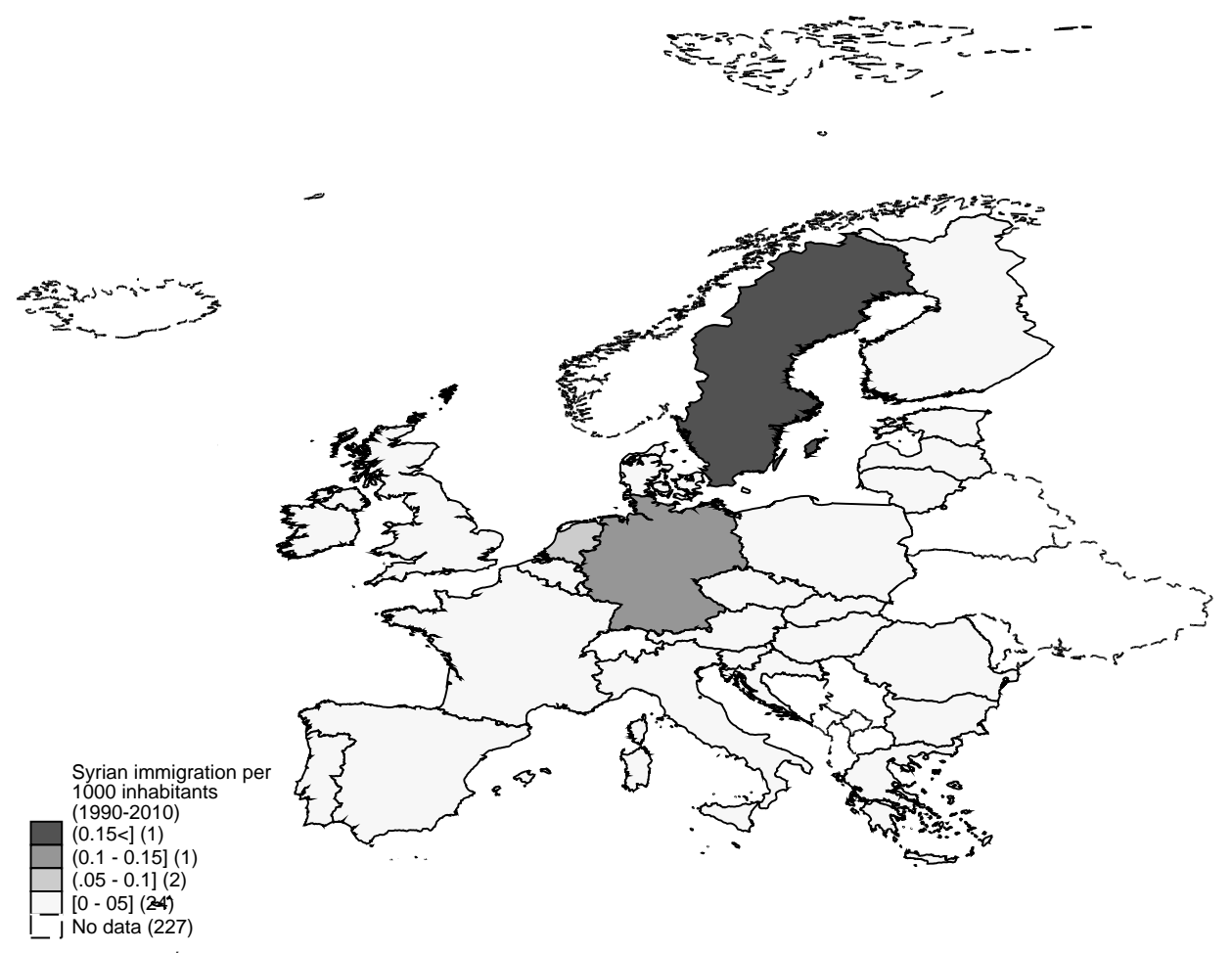

Note: Figure displays the average value in accepted Syrian asylum-seekers per 1000 inhabitant from 1990 to 2010. The figure suggest that Sweden and Germany had the largest reception of Syrians during the time period.

Source: Statistics on population size from Eurostat (2019) and statistics on accepted Syrian refugees from UNHCR (2019) 


\section{E Data sources}

The study uses several data sources. The Swedish Migration Agency (SMA) has information on the monthly, weekly and (although not analyzed here) daily number of asylum-seekers by citizenship. The SMA also hold data on the recognition rate for asylum-seekers as well as the number of recognized individuals in need of protection, who received either temporary or permanent residence permit over time. In addition to that, the SMA holds individual data regarding date of application, date of decision, and type of decision for all Syrian applicants.

For the number of asylum-seekers from Syria to Europe, we used EuroStat and data from UNHCR. Google trend data was used to measure the relative search frequency for "Sweden", "Germany" and other relevant terms during 2013. The data over verified deaths in Syria was collected from humanitarian tracker.

To be able to study the change in individual characteristics on those arriving before and after the reform, we used GeoSweden. GeoSweden is a data-base that holds information on all residents with a registered address in Sweden 1990-2014. The data is based on tax-registries, collected by Statistics Sweden, but administered by the Institute for Housing and Urban Research at Uppsala University. The data includes information on a variety of characteristics, such as labor market status, place of stay, income, immigration and demographic status. 